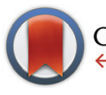

CrossMark

\&lick for updates

Cite this: Dalton Trans., 2015, 44

7135

Received 14th January 2015,

Accepted 12th March 2015

DOI: $10.1039 / \mathrm{c} 5 \mathrm{dt} 00175 \mathrm{~g}$

www.rsc.org/dalton

\section{Enhanced cancer cell killing of a Pt(Iv) prodrug promoted by outer-sphere coordination with polyethyleneimines $\uparrow$}

\author{
A. Garaikoetxea Arguinzoniz, ${ }^{a}$ N. Gómez Blanco, ${ }^{a}$ P. Ansorena Legarra ${ }^{a}$ and \\ J. C. Mareque-Rivas ${ }^{\star a, b}$
}

The cisplatin prodrug $c, c, t-\left[\mathrm{Pt}\left(\mathrm{NH}_{3}\right)_{2} \mathrm{Cl}_{2}\left(\mathrm{O}_{2} \mathrm{CCH}_{2} \mathrm{CH}_{2} \mathrm{CO}_{2}\right)_{2}\right]^{2-}$ (1) forms outer-sphere coordination interactions with non-toxic low MW PEl, which results in enhanced cancer cell killing, also achieved using PEl-coated AuNPs.

Cisplatin stands as one of the most commonly used and few chemotherapeutic agents with broad efficacy for cancer treatment. ${ }^{1}$ Despite its clinical success there are several limitations to its use, including limited selectivity, development of side effects and resistance mechanisms. An emerging trend to develop a new generation of platinum-based drugs overcoming the limitations of the highly reactive Pt(II) drugs is to use inert $\mathrm{Pt}(\mathrm{Iv})$ prodrugs that can be reduced inside cancer cells. ${ }^{2}$ Over the past few years several $\mathrm{Pt}(\mathrm{Iv})$ prodrugs have been attached to different types of nanoparticles to facilitate their delivery and activation. ${ }^{3,4}$ Considering that platinum-based drugs are rarely used as single agent chemotherapy and cannot be detected non-invasively in vivo, there is major potential in developing more efficient combinatorial and multimodal therapies, and methods which can facilitate tracking these constructs in vivo using clinical molecular imaging techniques. AuNPs are attracting considerable interest in cancer research because of their excellent biocompatibility and applicability in photothermal therapy and radiotherapy, as well as for in vitro and in vivo imaging under both visible/NIR irradiations and X-ray voltage sources used for diagnostic X-ray examinations. ${ }^{5}$

The most important biomedical application of polyethyleneimines (PEIs) is in gene therapy to promote the efficient internalization and trafficking of nucleic acid molecules by cells. ${ }^{6}$ PEIs have become the "gold standard" in non-viral gene delivery for their ability to provide high positive charge density

\footnotetext{
${ }^{a}$ Theranostic Nanomedicine Laboratory, CIC biomaGUNE, Paseo Miramón 182, 20009 San Sebastián, Euskadi, Spain. E-mail: jmareque@cicbiomagune.es; Tel: +34 943005313

${ }^{b}$ Ikerbasque, Basque Foundation for Science, 48011 Bilbao, Euskadi, Spain $\dagger$ Electronic supplementary information (ESI) available: Full experimental details and additional characterization and cytotoxicity data. See DOI: 10.1039/ c5dt00175g
}

that enables high nucleic acid binding and condensing capacity, high buffering capacity for endosomal escape ${ }^{7}$ and nuclear localization ability. ${ }^{8}$ PEIs are available in a wide range of molecular weights (MW) from 423 Da to $800 \mathrm{kDa}$ with branched or linear topologies. Generally, high MW PEIs have high transfection efficiency but also high toxicity. PEIs with a MW below $5 \mathrm{kDa}$ exhibit strongly reduced cytotoxicity but provide less efficient gene transfection. ${ }^{9}$

We report herein a new approach in medicinal inorganic chemistry and nanomedicine, which exploits supramolecular chemistry properties of anionic Pt(Iv) prodrugs to promote outer-sphere interactions with PEI. We show that a non-toxic low MW PEI (1.8 kDa) is capable of promoting the intracellular redox activation of $c, c, t-\left[\mathrm{Pt}\left(\mathrm{NH}_{3}\right)_{2} \mathrm{Cl}_{2}\left(\mathrm{O}_{2} \mathrm{CCH}_{2} \mathrm{CH}_{2} \mathrm{CO}_{2}\right)_{2}\right]^{2-}$ (1) to enhance cancer cell killing. We apply this novel outersphere drug activation approach to deliver and activate (1) using PEI-capped gold nanoparticles (AuNPs) readily prepared in a single step by incubating the $1.8 \mathrm{kDa}$ PEI with an aqueous solution of $\mathrm{HAuCl}_{4}$ at $90{ }^{\circ} \mathrm{C}$ for $2 \mathrm{~h}$. This $\mathrm{Pt}(\mathrm{rv})$ complex was selected because it has suitable ligands to participate in multiple non-covalent outer-sphere interactions with PEI (Scheme 1). More importantly, (1) is considered an excellent prodrug for the archetypical drug cisplatin as it is stable enough to travel through the bloodstream until it reaches a tumor cell without premature decomposition. ${ }^{2}$ To elucidate the relative importance of each of the ligand types present in the inner-sphere of (1) in promoting the outer-sphere interactions with the PEI polymer, two other clinically relevant $\mathrm{Pt}(\mathrm{Iv})$ complexes, c,c,t-[Pt( $\left.\left.\left(\mathrm{NH}_{3}\right)_{2}\left(\mathrm{OCH}_{2} \mathrm{CO}_{2}\right)\right)\left(\mathrm{O}_{2} \mathrm{CCH}_{2} \mathrm{CH}_{2} \mathrm{CO}_{2}\right)_{2}\right]^{2-}$ (2) and $c, c, t-\left[\mathrm{Pt}\left(\mathrm{NH}_{3}\right)_{2} \mathrm{Cl}_{2}(\mathrm{OH})_{2}\right](3)$, are also investigated.

Cyclic voltammetry studies in PBS ( $\mathrm{pH}$ 7.4) showed that interactions with PEI shift the reduction potential of (1) by as much as $+500 \mathrm{mV}$ (Fig. S1 and S2, ESI $\dagger$ ), which is indicative of the direct influence of multiple H-bonding interactions. ${ }^{10,11}$ In this Pt(Iv) complex all the ligands can contribute to the outersphere interaction with PEI. In addition to two carboxylates that give an overall -2 charge at neutral $\mathrm{pH}$ to provide strong electrostatic attraction with the positively charged PEI polymer, (1) has chloro ligands which have been shown to be 


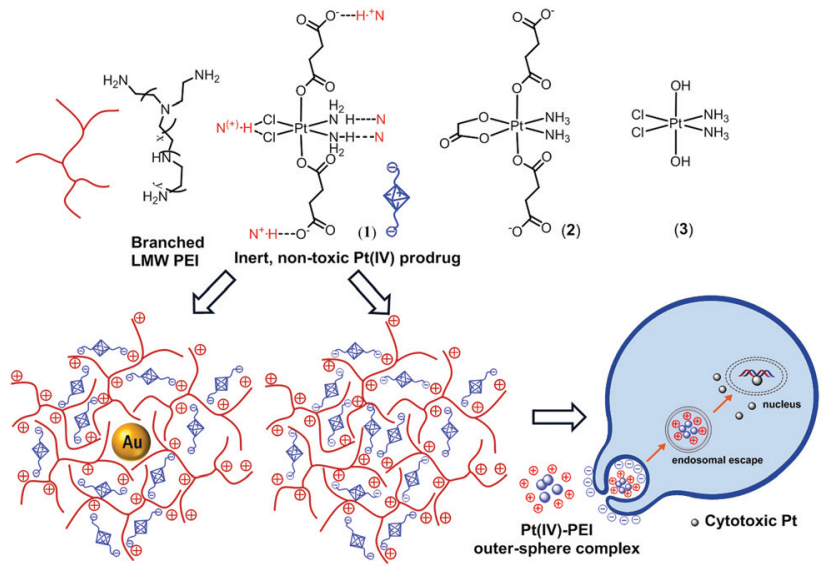

Scheme 1 Structure of PEI, (1), (2) and (3), plausible supramolecular synthons involved in the formation of $\mathrm{PEI}$-(1) outer-sphere complexes and cancer killing mechanism.

excellent $\mathrm{H}$-bond acceptors, in particular when they are located cis to each other. ${ }^{12}$ Additionally, the two amines through coordination to the high valent $\mathrm{Pt}(\mathrm{Iv})$ centre and $\mathrm{N}-\mathrm{H} \cdots \mathrm{Cl}-\mathrm{Pt}$ $\mathrm{H}$-bonding should have enhanced acidity to act as $\mathrm{H}$-bond donors. $^{10}$

NMR studies showed that addition of ascorbate, a biological reductant, results in the appearance of a peak due to free succinic acid in a time-dependent manner (Fig. 1). The intensity of this peak is higher in the presence of PEI. Notably, when the $\mathrm{pH}$ of the solution was adjusted from $\mathrm{pH} 3-4$ (i.e. (1) added in the fully protonated form) to $\mathrm{pH} \mathrm{7,} \mathrm{the} \mathrm{effect} \mathrm{of} \mathrm{PEI}$ towards promoting the release of succinate was even more pronounced. In view of the $\mathrm{p} K_{\mathrm{a}}$ values reported for branched PEI (4.5 for primary, 6.7 for secondary, and 11.6 for tertiary amine groups $)^{13}$ at $\mathrm{pH}<4$ PEI is in its fully protonated form. At these $\mathrm{pH}$ values the terminal carboxylates of (1) are also protonated (Fig. S3, ESI $\dagger$ ), and therefore, the neutral Pt(Iv) complex most likely interacts less strongly with the cationic PEI. In addition to weaker electrostatic interactions it is reasonable to expect

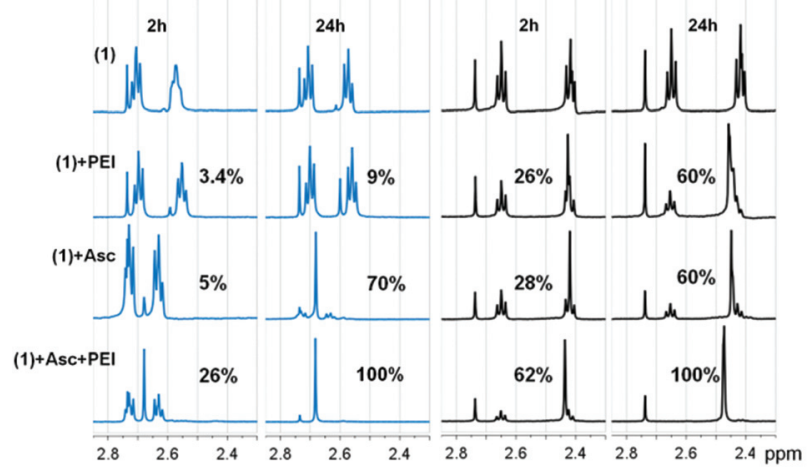

Fig. 1 Changes in ${ }^{1} \mathrm{H}$ NMR spectrum of (1) (1 mM) in $\mathrm{D}_{2} \mathrm{O}$ at $\mathrm{pH} 3-4$ (blue) and $\mathrm{pH} 7$ (black) in the presence and absence of PEI (10 $\mu \mathrm{M})$ and ascorbic acid (10 $\mathrm{mM})$. that at this $\mathrm{pH}$, protonation of the $\mathrm{N}$ atoms of PEI may also be preventing the formation of $\mathrm{Pt}-\mathrm{NH}_{3} \cdots \mathrm{N}$ hydrogen bonding interactions. In contrast, at $\mathrm{pH} 7$ the succinic acid groups of (1) are deprotonated and only a fraction of the $\mathrm{N}$ atoms are protonated (ca. 35\%), making it feasible the formation of the different synergistic outer-sphere interactions. As it can be expected from the release of succinic acid and the "proton sponge" properties of PEI, over time the $\mathrm{pH}$ of the mixture becomes more acidic ( $\mathrm{pH} 5.5$ at $24 \mathrm{~h}$ ). The ability of PEI to promote rapid (within minutes) and efficient internalization and trafficking of nucleic acid-based drugs by cancer cells is well-known.

To elucidate the oxidation state of the platinum products we carried out XPS at the Pt $4 \mathrm{f}$ region. The spectra of (1), which presents peaks at $78.9 \pm 0.2 \mathrm{eV}\left(4 \mathrm{f}_{5 / 2}\right)$ and $75.5 \pm 0.2 \mathrm{eV}$ $\left(4 \mathrm{f}_{7 / 2}\right)$, after the addition of ascorbate and PEI, showed the appearance of peaks at $76.4 \pm 0.3 \mathrm{eV}\left(4 \mathrm{f}_{5 / 2}\right)$ and $73.1 \pm 0.3 \mathrm{eV}$ $\left(4 \mathrm{f}_{7 / 2}\right)$ indistinguishable from those of cisplatin (Fig. S4, ESI $\dagger$ ). Notably, the concentration of Pt(II) species calculated using XPS after $24 \mathrm{~h}$ is $\mathrm{ca}$. $73 \%$. This result indicates that some succinate is liberated from (1) without reduction. Although the design of $\mathrm{Pt}(\mathrm{Iv})$ prodrugs is based on the assumption that the cytotoxic Pt(II) drug is obtained by clean loss of the two axial ligands, recent studies have shown that these assumptions need to be reassessed as other products can also be formed. ${ }^{14}$

Next, by using the $1.8 \mathrm{kDa}$ PEI both as the reductant and the stabilizer we could prepare in a single step PEI-capped AuNPs (PEI-AuNPs). ${ }^{15}$ When PEI was incubated with an aqueous solution of $\mathrm{HAuCl}_{4}$ at $90{ }^{\circ} \mathrm{C}$ for $2 \mathrm{~h}$ it formed PEI-AuNPs with an absorption band at $521 \mathrm{~nm}$ related to the surface plasmon resonance (Fig. $2 \mathrm{c}$ and S5, ESI $\dagger$ ). Transmission electron microscopy studies (TEM) showed non-aggregated spherical PEI-AuNPs of $9.8 \pm 1.8 \mathrm{~nm}$ (Fig. 2a,b and S6,
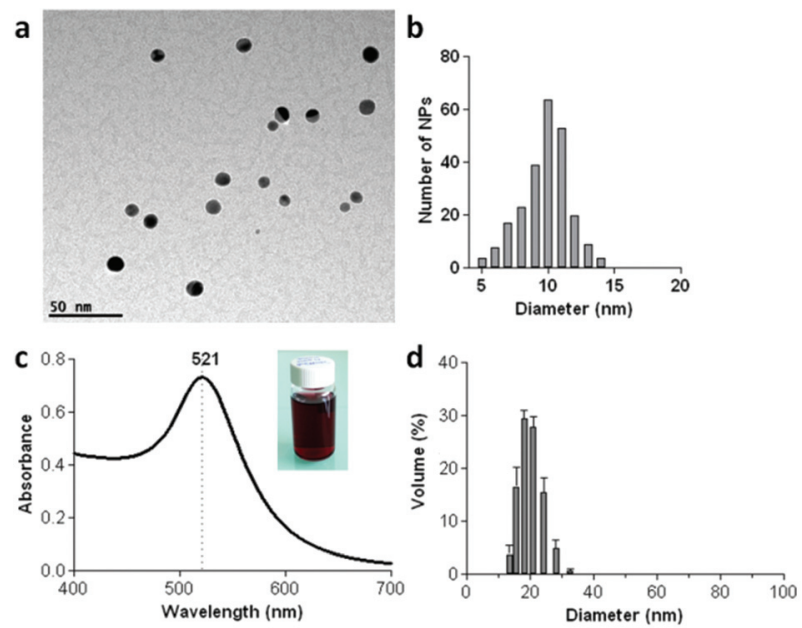

Fig. 2 Main features of the synthesized PEl-capped AuNPs (PEI-AuNPs). (a) TEM image and (b) size distribution histogram showing an average diameter of $9.8 \pm 1.8 \mathrm{~nm}$. (c) UV-Vis spectra showing the surface plasmon resonance at $521 \mathrm{~nm}$ with a representative photograph of the PEI-AuNPs in water (inset) and (d) hydrodynamic diameter. 
ESI $\dagger$ ). The hydrodynamic diameter of the PEI-AuNPs in water was measured by dynamic light scattering (DLS). The PEI-AuNPs had an average diameter of $c a .19 .9 \mathrm{~nm} \pm 1.1 \mathrm{~nm}$ with relatively narrow size distribution (polydispersity index $(\mathrm{PDI})=0.331 \pm 0.035)$. The zeta potential studies confirmed the presence of the positively charged PEI on the AuNPs (zeta potential $=+34.15 \pm 0.48 \mathrm{mV}$ ). As expected from the presence of the negatively charged Pt(Iv) prodrug, the surface charge changed to less positive values after addition of $100 \mu \mathrm{M}$ (1) (zeta potential $=+13.7 \pm 0.52 \mathrm{mV}$ ). To investigate the cellular internalization behaviour of these PEI-AuNPs, we modified the PEI with fluorescein isothiocyanate (FITC) as described elsewhere $^{16}$ (ESI $\dagger$ ) and we examined the cellular uptake in cancer cells by fluorescence microscopy and fluorescence activated cell sorting (FACS). These studies showed that PEI-AuNPs and PEI-AuNPs/(1) outer-sphere complexes are effectively taken up by the cancer cells already after $45 \mathrm{~min}$ incubation (Fig. S7 and S8, ESI†).

We investigated the ability of these novel outer-sphere coordination complexes to kill different human cancer cells (the highly aggressive prostate cancer cell, $\mathrm{PC}-3$; the pancreatic cancer cell line, PANC-1 and a well-known human breast cancer cell line, MDA-MB231) by using the SRB assay. The PEI vehicle, PEI-AuNPs and (1) had negligible in vitro cytotoxicity even after incubation for $72 \mathrm{~h}$ (Fig. 3). However, the results showed that the cell-killing ability of the inert Pt(Iv) prodrug (1) is significantly enhanced in the three human cancer cell lines when is delivered by PEI and PEI-AuNPs (Fig. 3 and S9, ESI $\dagger)$. In contrast, PEI had no effect on the cancer cell-killing ability of the neutral complex (3) (Fig. S10, ESI $\dagger$ ). In agreement with the NMR studies, this result suggests that interactions arising from the anionic succinate ligands are important for stabilizing the PEI-(1) outer-sphere complexes. To elucidate the importance of the chloro ligands we prepared and tested (2), which is a prodrug for another clinically used Pt(II) drug,

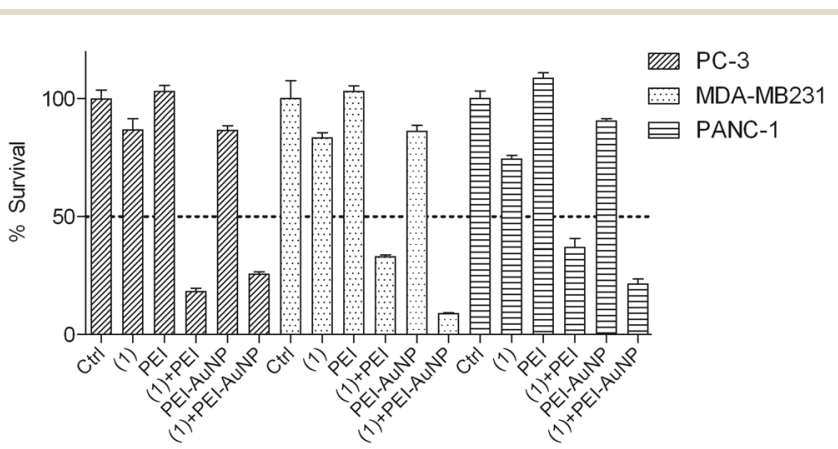

Fig. 3 Cytotoxicity of PEI, PEI-AuNPs, PEI-(1) and PEI-AuNP-(1) outer sphere complexes in PC-3, MDA-MB231 and PANC-1 cells after $72 \mathrm{~h}$. $[(1)]=100 \mu \mathrm{M},[\mathrm{PEI}]=1 \mu \mathrm{M},[\mathrm{Au}(0)]=10 \mu \mathrm{M}$. In the (1) $+\mathrm{PEI}$ and $(1)+$ PEI-AuNP systems the stock solutions of (1) and PEI or (1) and PEI-AuNPs were mixed in water for 30 min, diluted 1/10 in cell culture medium and directly added to the cells without purification to provide $[(1)]=100 \mu \mathrm{M}$ and $[\mathrm{PEI}]=1 \mu \mathrm{M}$ or $[(1)]=100 \mu \mathrm{M}$ and $[\mathrm{Au}(0)]=10 \mu \mathrm{M}$ to the cells. Results are the means \pm SEM from three independent experiments performed in quintuplets. nedaplatin. Addition of PEI increased the cell-killing ability of (2) only in the MDA-MB231 cells and to much less extent than for (1) (Fig. S11, ESI $\dagger$ ). Thus, interactions with the two cischloro ligands are important in promoting the formation of the PEI-(1) outer-sphere complexes.

In conclusion, we have demonstrated here that outer-sphere coordination chemistry can be applied to promote intracellular delivery and activation of a Pt(Iv) prodrug using a non-toxic LMW PEI. The PEI-Pt(Iv) prodrug outer-sphere complex seems to be promoted by interactions with each of the first coordination sphere ligands, and results in more facile reduction to $\mathrm{Pt}(\mathrm{II})$, succinate release and significantly enhanced cytotoxicity in several human cancer cell lines. The significance of these findings lies in the wide range of available PEI-derived compounds and PEI-modified drug delivery vehicles as well as $\mathrm{Pt}$ (Iv) prodrugs which can be used for tuning and applying successfully this novel outer-sphere coordination chemistry approach for clinical applications. Delivering and activating the Pt(Iv) prodrugs with PEI-capped AuNPs in particular, opens up fascinating opportunities to combine synergistically gene therapy with chemotherapy, and chemotherapy with radiotherapy or photothermal therapy. Moreover, since the suitability of AuNPs as X-ray and multimodal contrast agents has been demonstrated in live animals, by using PEI-capped AuNPs as delivery vehicles it may be possible to concurrently monitor the efficacy of tumor delivery and whether this is responding to the treatment using current clinical molecular imaging approaches.

This work was supported by the Ministerio de Economia y Competitividad (MINECO, Spain) (grant CTQ2011-22723), the Department of Industry of the Basque Country (grant ETORTEK) and the Department of Education, Universities and Research of the Basque Country (grant PI-2012-33).

\section{Notes and references}

1 E. R. Jamieson and S. J. Lippard, Chem. Rev., 1999, 99, 2467; L. Kelland, Nat. Rev. Cancer, 2007, 7, 573; S. J. Berners-Price, Angew. Chem., Int. Ed., 2011, 50, 804; M. Galanski, M. A. Jakupec and B. K. Keppler, Curr. Med. Chem., 2005, 12, 2075.

2 M. D. Hall and T. W. Hambley, Coord. Chem. Rev., 2002, 232, 49; N. Graf and S. J. Lippard, Adv. Drug Delivery Rev., 2012, 64, 993.

3 C. Sanchez-Cano and M. J. Hannon, Dalton Trans., 2009, 10702; X. Wang and Z. Guo, Chem. Soc. Rev., 2013, 42, 202; C. R. Maldonado, L. Salassa, N. Gomez-Blanco and J. C. Mareque-Rivas, Coord. Chem. Rev., 2013, 257, 2668; N. P. E. Barry and P. J. Sadler, ACS Nano, 2013, 7, 5654.

4 S. D. Brown, P. Nativo, J.-A. Smith, D. Stirling, P. R. Edwards, B. Venugopal, D. J. Flint, J. A. Plumb, D. Graham and N. J. Wheate, J. Am. Chem. Soc., 2010, 132, 4678; Y. Min, C. Mao, D. Xu, J. Wang and Y. Liu, Chem. Commun., 2010, 46, 8424; W. J. Rieter, K. M. Pott, K. M. L. Taylor and W. Lin, J. Am. Chem. Soc., 2008, 130, 
11584; S. Dhar, W. L. Daniel, D. A. Giljohann, C. A. Mirkin and S. J. Lippard, J. Am. Chem. Soc., 2009, 131, 14652; Y. Min, C.-Q. Mao, S. Chen, G. Ma, J. Wang and Y. Liu, Angew. Chem., Int. Ed., 2012, 51, 6742; Y. Shi, J. Goodisman and J. C. Dabrowiak, Inorg. Chem., 2013, 52, 9418; C. R. Maldonado, N. Gomez-Blanco, M. Jauregui-Osoro, V. G. Brunton, L. Yate and J. C. Mareque-Rivas, Chem. Commun., 2013, 49, 3985; E. Ruggiero, J. Hernandez-Gil, J. C. Mareque-Rivas and L. Salassa, Chem. Commun., 2015, 51, 2091.

5 R. A. Sperling, P. Rivera Gil, F. Zhang, M. Zanella and W. J. Parak, Chem. Soc. Rev., 2008, 37, 1896; E. Boisselier and D. Astruc, Chem. Soc. Rev., 2009, 38, 1759; X. Huang, I. H. El-Sayed, W. Qian and M. A. El-Sayed, J. Am. Chem. Soc., 2006, 128, 2115; S. Jain, D. G. Hirst and J. M. O’Sullivan, Br. J. Radiol., 2012, 85, 101; J. F. Hainfeld, M. J. O'Connor, F. A. Dilmanian, D. N. Slatkin, D. J. Adams and H. M. Smilowitz, Br. J. Radiol., 2011, 84, 526; S. Setua, M. Ouberai, S. G. Piccirillo, C. Watts and M. Welland, Nanoscale, 2014, 6, 10865.

6 R. Kircheis, L. Wightman and E. Wagner, Adv. Drug Delivery Rev., 2001, 53, 341; C. L. Gebhart and A. V. Kabanov, J. Controlled Release, 2001, 73, 401; M. Neu, D. Fischer and T. Kissel, J. Gene Med., 2005, 7, 992.

7 O. Boussif, F. Lezoualc'h, M. A. Zanta, M. D. Mergny, D. Scherman, B. Demeneix and J. P. Behr, Proc. Natl. Acad.
Sci. U. S. A., 1995, 92, 7297; N. D. Sonawane, F. C. Szoka Jr. and A. S. Verkman, J. Biol. Chem., 2003, 278, 44826.

8 S. Brunner, E. Furtbauer, T. Sauer, M. Kursa and E. Wagner, Mol. Ther., 2002, 5, 80.

9 K. Kunath, A. von Harpe, D. Fischer, H. Petersen, U. Bickel, K. Voigt and T. Kissel, J. Controlled Release, 2003, 89, 113.

10 D. Natale and J. C. Mareque-Rivas, Chem. Commun., 2008, 425; L. Metteau, S. Parsons and J. C. Mareque-Rivas, Inorg. Chem., 2006, 45, 6601.

11 I.-J. Lin, E. B. Gebel, T. E. Machonkin, W. M. Westler and J. L. Markley, Proc. Natl. Acad. Sci. U. S. A., 2005, 102, 14581.

12 L. Brammer, J. K. Swearingen, E. A. Bruton and P. Sherwood, Proc. Natl. Acad. Sci. U. S. A., 2002, 99, 4956; J. C. Mareque Rivas and L. Brammer, Inorg. Chem., 1998, 37, 4756.

13 K. D. Demadis, M. Paspalaki and J. Theodorou, Ind. Eng. Chem. Res., 2011, 50, 5873.

14 E. Wexselblatt and D. Gibson, J. Inorg. Biochem., 2012, 117, 220.

15 X. Sun, S. Dong and E. Wang, J. Colloid Interface Sci., 2005, 288, 301.

16 P. C. Pinheiro, A. L. Daniel-da-Silva, D. S. Tavares, M. P. Calatayud, G. F. Goya and T. Trindade, Materials, 2013, 6, 3213. 